\title{
Die moeder-kind verbintenis
}

\author{
E.M. Maclure \\ Prinsipale, Mowbray-Kraamhospitaal, Kaapstad.
}

\section{SUMMARY}

In antenatal clinics, maternity homes and doctors' practices, more can be done to promote understanding of the patient's needs and of the lack of mother-child bonding factors.

The importance of early experiences which create a bond bet ween mother and baby cannot be sufficiently stressed. The sooner the mother is allowed to handle, inspect and suckle her baby, the less complicated will be the most important first impression and the easier the development of mutual care.

"Ik ween om bloemen, in den knop gebroken En voór den ochtend van haar bloei vergaan. Ik ween om liefde, die niet is ontloken. En om een harte dat niet wordt versian."

\section{— Willem Kloos}

$\mathbf{E}$ LKEEN is die produk van sy verlede en een van die paradokse van menswees is dat die pasgeborene 'n verlede het voordat hy 'n toekoms het. Deur die tye heen het die misterium en die praktikaliteit van kindwees en van ouers-van-kinders wees vir filosowe, digters, skrywers, dramaturge, medici en psigologe en alle denkers besig gehou. In mites en legendes speel die gekompliseerde genealogie van die gode en hulle verhoudings met 'n verskeidenheid afstammelinge alreeds die hoofrol. Die Griekse skrywers verewig die ouer-kind verhouding in aangrypende dramas - Oedipus, Iphigenia, Antigone; in die boek van Genesis word hoofstukke gewy aan wie die kinders van wie is; deur die donker eeue, die middel eeue, die Renaissance, die politieke en industriële rewolusies, tot in hierdie deel van die opwindende twintigste eeu, bly ouer-kinder verbintenisse betowerend in hulle oneindige verskeidenheid en kompleksiteit.

Die grootste probleem in die intellektuele benaderings tot hierdie mees fundamentele menslike verhouding is dat dit die gevolg is van diepgaande interaksie tussen onvoorwaardelik-verbonde personlikhede wat voortdurende deining meebring; inherent hierin is groei en kwyning, ontwikkeling en vertraging, vrystelling en inhibisie, ongekende vreugde en smart.

Met die voorafgaande, ' $n$ belydenis van eerbied teenoor kinders en hulle ouers, kan ten beste 'n stelselmatige opsomming aangedurf word deur die hedendaagse denke en geskrifte te benader met betrekking tot faktore wat die moeder-kind verhouding beïnloed; die ontwikkeling daarvan tydens swangerskap; die effek van baring; die aan- passings van die puerperium en tuiskoms as gesin; die instandhouding tydens vroeë kinderdae en in die voorskoolse tydperk. Deurgaans sal, hopelik, die rol van die vroedvrou, die gemeenskapsgesondheidsverpleegkundige en talle gemoeide persone deurskemer, maar nie predomineer nie. Met die Natuur, solank sy haar gedra, hoef nie te veel ingemeng te word nie, maar daar is sommige van Gods akkers waaroor die water nog gelei en nie net laat loop met word nie.

Gehegtheidsgedrag is wederkerig tussen moeder en kind uit die afhanklikheid van die een en die verantwoordelikheid van die ander. Indien die eenhede hierby betrokke nie liefdesvermoë het nie, kan dié ingeboude element van verpligting alreeds 'n voorbehoud laat ontwikkel en sodoende word die kiem van algehele oorgawe en erkenning vroeg gesmoor

Faktore wat hierdie gedrag, gegrond op die onderliggende sielkunde, affekteer, sluit die volgende in:

Die familiegeskiedenis van die swanger vrou beïnvloed haar houding teenoor ouerskap. Haar eie posisie as oudste, jongste of enigste in haar ouerhuis sal byvoorbeeld 'n patronerende uitwerking hê volgens haar moeder se benadering tot voortplanting en ouerskap. Die verlies van 'n ouer op ' $n$ jong leeftyd met gevolglike verantwoordelikheid vir jonger gesinslede, of ervarings as stiefkind, kan dit vir haar moeiliker maak om haar eie moederskap te aanvaar en vereis groter ondersteuning deur haar eggenoot. Dan weer kan 'n nuwe moeder skerp reageer op inmenging deur eie- of skoonmoeder, hoe welwillend ook al, terwyl sy tog behoefte aan gerusstelling en emosionele warmte het deur ouer vroue wat al self die ondervinding suksesvol beleef het.

Haar persoonlikheid voor swangerskap gee 'n aanduiding van haar moontlikhede om betekenisvolle menslike verhoudings in stand te hou. Transisie van meisie tot vrou tot eggenote tot moeder gebeur makliker in iemand wat kon aanpas van kindsbeen af. Daarenteen kan neurotiese reaksies verminder met pariteit eneteit, alhoewel depressies 'n neiging het om te herhaal en te vererger, veral in die puerperium. 
Kulturele agtergrond, gepaard met die omstandighede van die swangerskap, (hetsy beplan; onbeplan maar gewens in 'n hoë persentasie van gevalle of onbeplan en ongewens) bepaal die aanvaarbaarheid van haar toestand van ooglopende vrugbaarheid in haar nabye omgewing en samelewing. Dit beïnvloed weer haar aanvaarding van die kind. So ook die kwaliteit van die verhouding met die vader.

Sosio-ekonomiese aspekte van 'n gesinstoevoeging mag ingrypende finansiële gevolge hê indien die moeder haar studies, loopbaan of werk moet staak en kan sodoende veral in ' $n$ materiële samelewing haar benadering tot haar kind verwar indien sy nie die nodige aanmoediging kry vir die waardeverandering om na die geboorte van haar kind uit te sien nie.

Die stabiliteit van leefwyse is belangrik om 'n atmosfeer van veiligheid te handhaaf tydens swangerskap en die versorging van 'n klein baba. 'n Verhuising met die gepaardgaande ontworteling tydens die tweede trimester se "nesbou"-instink, of die fisiese uitputting daarvaan in laat swangerskap of vroeë moederskap kan 'n nadelige effek op haar emosionele response tot haar kind hê. Hospitalisasie veroorsaak emosionele stremming behalwe in die ontspanne multigravida wat dit as 'n vakansie beskou. Blote onbedagsaamheid van personeel kan as beledigend of verwerpend interpreteer word. Veral voorgeboortelike hospitalisasie kan aanleiding daartoe gee dat die moeder haar fetus blameer vir haar predikament en dan weer skuldgevoelens ontwikkel wat 'n totale ambivalensie in haar bindingsvermoë bring. Dié onderliggende toestand mag ook bydra tot 'n voorbehoud teen die swangerskap omdat dit haar welsyn of self haar lewe bedreig. Kondisionering dat voortplanting 'n vrou se hoogste funksie is oortuig haar dus dat sy tot ultimale selfopoffering bereid behoort te wees.

Pariteit speel 'n groot rol. Die primigravida of die vrou met 'n vorige traumatiese verloskundige ondervinding sal natuurlik haar vermoë betwyfel om suksesvolle moeder te word en haar kind te versorg. Voorligting, ouerskapsonderrig en toegeneë insig van die personeel minimiseer die nadelige gevolge op haar houding.

Swangerskap is een van die drie periodes in die vrou se lewensiklus wat gekenmerk word deur 'n verminderde vermoë om emosionele ondervindings te hanteer en sy reageer dus sterker. Hierdie emosionele labiliteit kan tot 'n mate toegeskryf word aan fisiologiese veranderinge en die hoeveelheid sirkulerende hormone, indien die konsep van swangerskap as 'n somato-psigiese toestand aanvaar word. Emosionele sowel as ingrypende fisiese aanpassings is nodig, (selfs Napoleon het swaar gekry op twee fronte tegelyk!)

Terwyl die emosies van trots en ontluikende moederliefde kalmte en vreugde in die hand werk, kan dit uitgekanselleer word deur vrees, afkeuring en oggendmislikheid. Die effekte hang af van temperament, intelligensie, opvoeding, fisiese gesteldheid, ouderdom en huwelikstaat. Van die grootste belang is of die baba welkom is en die vooruitsigte op welgeskapenheid goed is.

Volgens Jung and Kerényi is die hegste ouer-kind verhouding soms tussen 'n vondeling en sy pleegouers omdat daar geen vertroebeling is deur wedersydse buitensporige verwagtings nie. Beide ouers en kind of kinders ontwikkel dus die verhouding tot sy volle potensiaal deur positiewe benaderings - die ouers bevredig die begeerte om 'n kind te versorg en lief te hê en die vondeling presteer uit 'n diep- gaande begeerte om sy dankbaarheid te betoon en homself te vind en te bewys sonder die bloedknoop verpligting.

In die eerste trimester word daar al definitiewe fondamente gelê vir die moeder-kind hegting deur die hantering van die bevestiging van swangerskap en hoe 'n vrou dit ondervind, vermoed, laat diagnoseer en hoe sy daarvaan verwittig word. Emosionele labiliteit tussen opgewondenheid en terneergedruktheid is ' $n$ kenmerk. Beëindiging van swangerskap op grond van neurotiese simptome word soms gedurende hierdie tydperk oorweeg. Sy kan in hierdie stadium nie objektief hieroor redeneer nie en mag in die meer stabiele tweede trimester die swangerskap heeltemal aanvaar.

Die eerste indruk wat die vrou kry van personeel, kliniek of hospitaal, beinvloed haar eie reaksie op haar toestand. As sy 'n natuurlike, vriendelike ontvangs geniet en die nodige vrae met takt en opregte belangstelling op professionele wyse gestel word, begin sy hou van haar embrio.

Die tweede trimester is vir die gesonde gelukkige vrou die aangenaamste deel van swangerskap. Die minder ernstige ongesteldhede van vroeë swangerskap neem af, sy lyk blakend gesond en die veranderinge in liggaamsvorm is subtiel en nog privaat. Sosiale aktiwiteit is nog nie ingekort nie en geleidelik word sy gewoond aan die fait accompli en met die gewaarwording van die eerste fetale bewegings begin 'n persoonlike verhouding met haar ongebore kind. Dit gee haar selfversekering, inspirasie en die begeerte om vir haar kind voor te berei. As sy hierin frustreer word deur omstandighede, benadeel dit hierdie belangrike fase van toeneiging en tenspyte van fisiese welsyn behoort die vroedvrou toe te sien dat sy hulp kry.

Die geforseerde verstadiging van die derde trimester, dikwels vererger deur meer of minder ernstige ongesteldhede, gee dan ook tyd vir angsgevoelens omtrent haar bevoegdheid om normaal te baar, verlies van waardigheid, verantwoordelikheid vir die sorge van 'n pasgebore baba en sy normaliteit. Daarby is minder volwasse of verwaande vroue dikwels bevrees dat hulle voorkoms en postuur permanent nadelig aangetas is en hulle begin om dit die baba te verkwalik. Die ongebore kind swem dus al in moederlike verwyte en die vooruitsig op 'n suksesvolle toekoms met sy ouers vervaag want as die vader dit dikwels genoeg hoor, mag hy dit begin glo en onvleiende vergelykings tref met ' $n$ nadelige invloed op die huwelikstoestand - alles is die kind se skuld, veral as sy 'n pragtige dogertjie is wat met moeder kompeteer vir vader se belangstelling. Die vroedvrou, geneesheer of gesondheidsopvoedster kan veel bydra deur die pasiënt gerus te stel oor die aanvaarbaarheid van haar voorkoms, die normaliteit van haar toestand en met 'n empatiese houding teenoor haar natuurlike vertwyfelings.

'n Moeder wat haar bevalling met redelike selfvertroue en versekering van goeie versorging en doeltreffende hantering tegemoet gaan en tydens die laaste trimester opgelei is in ouerkunde en psigoprofilakse, is al verlief op haar kind die dieper en blywende liefde wat haar die jare wat voorlê sal bybly, het "n intiemer, meer bewuste, direkte en sensuele samesyn nodig.

'n Vrou wat haar bevalling tegemoet gaan na 'n swangerskap waarin die eggenoot alreeds sy' versorgende en ondersteunende rol gespeel het deur bedagsame betrokkenheid, geduld met pika en allerlei nukke en grille en gunstig reageer het op die onbewuste toetse gestel aan sy liefde, toewyding en bereidheid om te hulp; wat ingelig en opgeles is om. haarselftydens baring oor te gee aan wat hopelik "n natuurlike 
proses is wat aangeleer het om op onnatuurlike wyse op pyn te reageer deur doelbewus te ontspan; en genoeg ouerkunde opgedoen het om uit te sien na die geboorte en versorging van haar kind - het alreeds 'n positiewe verbintenis met haar baba. So 'n ouerpaar het gewoonlik al 'n reeds denkbeelde oor hulle kind (wat natuurlik uniek gaan wees) en bespiegel oor die geslag, moontlike name en toekomsplanne as 'n gesin. Aangesien die vorming van 'n gesonde gesin afhang van ' $n$ reeks verbintenisse, is hierdie vroeë instelling daarop uiters belangrik:

moeder + vader: redes vir huwelik

moeder + baba: instinktief en natuurlik

baba + moeder:)

vader + baba:) moet aangeleer en aangemoedig word (Leboyer benadruk dit).

In voorgeboorte klinieke, kraaminrigtings en praktyk van dokters en vroedvroue kan meer gedoen word om perseptief te wees omtrent die behoeftes van die pasiënt en gebrek aan verbintenis-begunstigende faktore. By die Kinder- en Familie Eenheid van die Rooikruis-Hospitaal het Dor. Brian Robertson telkens gevind dat daar alreeds gedurende swangerskap aanduidings was dat ernstige probleme sou ontstaan en dat paslike optrede ten tye moontlik ernstige verhoudingsgebreke wat tot kindermishandeling en huweliks- of gesinsontwrigting lei, sou kon afweer of minimiseer. Sy ondervinding bring hom tot dieselfde gevolgtrekkings as alle ander studies (geneen baie wetenskaplik nie) gedoen deur Klaus en Kennell en Kennell en Klempe in Cleveland, V.S.A. en in verslae deur die Mothers' Centre of the Family Service Association of Nassau County, New York, onder leiding van Patsy Turrini.

Met die toelating van die pasiënt kan oplettendheid en opregte, verfynde pasiëntsorg (of kliënte- toewyding) alreeds boekdele spreek. Wie bring die vrou? Vra sy onmiddellik vrae? Soek sy alreeds gerusstelling omtrent die juistheid van haar kennis deur die simptome van aanvang van baring te herhaal en bevestiging te soek? Het haar begeleier 'n positief-beskermende houding wat vertroue inboesem? Is dit terapeuties of afbrekend indien hy aanvanklik meer vertroud skyn te wees met toelatingsprosedures (inagnemend die gewone man se houding teenoor hospitale) maar is daar kommunikasie dat netnou, wanneer sy swaarkry, hy die sterkere gaan wees? Word daar genoeg klem gelê op die belang van sy unieke ondersteunende rol en betrokkenheid om die manlike ego te streel en as't ware hierdie tere plant te voed? Dat sy teenwoordigheid verwelkom word deur dokter en vroedvrou en sy intieme kennis van sý vrou waardevol is? Dat daar praktiese take is wat hy kan uitvoer (dikwels tot sy vrou se verbasing!) maar wat die aanvang is van 'n nuwe fase in hulle verhouding deurdat die voorheen onhandige skielik lyk asof hy met sagte hand en blye gemoed sal help met luiers omruil, snags opstaan, baba bad ens. om waarlik te deel in die voltydse verantwoordelikheid van kindgrootmaak? Word daar op subtiele wyse by die aanvanklike krisissituasie voorsiening gemaak vir die deelname sonder verlies van waardigheid deur beide om tog onnodige skeiding en geheimsinnigheid te vermy?

Dic gegewens opgeteken en dieptenavorsing gedoen deur die Mothers" Centre het deurgaans getoon hoe moeders met verbintenisprobleme wat nie in die eerste week na kindergeboorte begin vervaag het nie, terugwys na onaangename en liggaamlik en geestelik traumatiese ervarings gedurende toelating, eerste vaginale ondersoek, vroeë baring in die "gewoondwordingstydperk" in die afwesigheid van die steunpilaar; hetsy eggenoot, haar eie moeder, geneesheer, vroulike sorg-figuur of bekende, vriendelike personeel. In Duitse kraamhospitale (Frauen Kliniken) vind 'n mens die voorligtingsdokument vir die sogenoemde "Badegespräch" - $n$ beleefdbewoorde ondervragingsgesprek tussen verpleegkundige en kliënt tydens die toelatingshigiëneprosedures. Na afloop hiervan behoort daar beslis (met kenmerkende deeglikheid) onderlinge bekendmaking en persoonlikheidsbeoordeling te wees!

Daar moet deurgaans gewaak word teen die ontstaan van 'n begrip dat die pasiënte (vrou en baba) nou " aan die hospitaal en ander mense behoort" met ontneming van reg en voorreg asof eie denke, voorkeure en behandeling deur moeder, vader en kind 'n oortreding is, in plaas van ' $n$ bron waaruit veel konstruktiefs en insiggewends geput word deur verfyninggestelde professionele versorgers.

Tydens die eerste stadium van baring is die aanwesigheid van ' $n$ verteenwoordiger van die mensdom egter nie voldoende nie. Die nodige "T.L.C." moet gepaard gaan met doeltreffende waarnemings en veral aandag aan paslike sedasie, analgesie en kalmeermiddels gegee word. Die aanbieding daarvan en die indruk dat dit redelik is om sulke middels nodig te hê en dit nie dui op swakheid, pieperigheid of ontoereikenheid nie, help 'n vrou om sonder skuld- en minderwaardigheidsgevoel deel te neem aan wat ten slotte hoofsaaklik háár prosedure is!

Deurlopende verduideliking, aanmoediging en positiewe voorspelling sonder leuns, gepaard met ooglopende vaardigheid, kennis en intelligensie plus die vermoë om ongemak en pyn te verlig is die grootste bydraes tot gerusstelling van die kraamvrou. Keer op keer word gekla dat sy soos 'n voorwerp gevoel het en dat onsydigheid blykbaar deur oormatige sedasie gemasker word, met gevolglike afbreuk aan die grootste eenmalige ondervinding tussen moeder en kind. Stel-die-pasiënt-en-gesinslede-gerus word een van die grootste betekenislose clichés wat deur elke verpleegkundige in elke vraestel en tesis geskryf word.

Indien die moeder se fisiologiese homeostase nie instandgehou word gedurende die lang ure van die eerste stadium nie, is sy fisies nie in staat om die groot oomblik van die geboorte mee te maak as 'n wonderlike, vreugdevolle ervaring nie. Verlossing is eenmelig en onherhaalbaar en as haar baba gebore is kah dit nie oorgedoen word om tegniek te verbeter nie.

Die gunstige verloop van die eerste stadium, gevolg deur die klimaks van die geboorte in die tweede stadium, waar hulle baba vir die eerste keer 'n sigbare werklikheid word, behoort deur almal as 'n eerbiedwaardige en ootmoedige oomblik erken te word. Geboorte is miskien die wonder van die lewe, maar die opbou daartoe en die gesindheid wat die baba inwag tydens die eerste kritiese minute en ure, word sonder meer aanvaar as deurslaggewend aan die ontwikkeling van suksesvolle, onbreekbare moeder-en ouerskind verbintenis

Alhoewel Frédérick Leboyer skuldig is aan veel emosionele oordrewenheid en volg in die spore van La Maze en Grantley Dick Read, het die beginsels wat hy voorhou validiteit.

Dit is onmoontlik om op variasies en katastrofes in te gaan, maar weereens is die grootste faktor in ouers se aanvaarding van 'n abnormale, hoë risiko of doodgebore baba, die onmiddellike reaksie van die bystanders.

Die onuitwisbare indrukke van die eerste oomblikke en dié oorlaaide emosionele krisis is lewenslank en beïinvloed ouers se verbintenisse met vorige en toekomstige kinders. 
Die belang van die vroeë verbintenis-skeppende ervarings tussen moeder en baba kan nie oorbeklemtoon word nie. Hoe gouer die moeder toegelaat word om haar baba te hanteer, inspekteer en soog, hoe minder gekompliseerd die allerbelangrikste eerste imprintasie en hoe makliker die ontwikkeling van onderlinge sorg-elisiterende gedrag. Die gesonde, gelukkige moeder se natuurlike response is feitlik 'n weerklank van die verloskundige inspeksie, betasting en ouskultasie van die voorgeboortesorg, indat sy haar kind dadelik besigtig in die kenmerkende en face parallel posisie, gewoonlik die handjies en voetjies teer ondersoek en dan bewonderend die lyfie streel (en hopelik die normale lagweë en stembande hoor)! Natuurlik is die verwonderde, bewoë uitgeputte maar supertrotse meedoen van eggenoot - nou vader in volle $\sin$ - intrinsiek.

Een van die voordele van die klem wat gelê word op skoonmaak en plasentaondersoek is die geleentheid wat dit die nuwe familie gee om 'n mate van eenheids-intimiteit te geniet. Die geleentheid om 'n paar stil, heilige oomblikke in 'n omgewing waaruit die bloed en drama verdwyn het, te beleef, behoort vanselfsprekend as 'n soort vyfde stadium van kindergeboorte ingestel te word. Soos alreeds gemeld dit kan die oorgedoen word nie en die geboorte van 'n ánder kind is weereens uniek en nie slegs 'n herháálde ondervinding nie.

Wanneer moeder en kind dan weer na roetine prosedures nerenig is, is die belang van borsvoeding se meegaande liggaamsbevrediging van BEIDE moeder en kind nie oor te beklemtoon nie.

Eietydse gebruik is immers om die moeder by die kind en kind by moeder te hê sover prakties moontlik is. Die saambly-beleid, moedersorgbeleid of inkamersorg (soos "rooming-in" ookal in sy onverstaanbaarheid genoem word) met die bygaande praktyk van aanvraagvoeding word algemeen aanvaar en die teenwoordigheid van moeders in oorjasse in intensiewe sorg eenhede-en areas is nie buitengewoon nie en is van onskatbare waarde in die instandhouding van die moeder-baba verbintenis ingeval van sulke sorgbehoewende kinders.

'n Tabel vir ouer-baba interaksie-telling is opgestel deur Gray, Cutler, Dean en Kempe:
Om ooglopende redes is dit nog altyd 'n taamlik subjektiewe bepaling, maar dit kan as 'n standaard toegepas word in areas waar probleme dikwels voorkom. Dit is uiters belangrik dat ouers wat nie 'n oorweldigende emosionele onrrompeling voel nie by die eerste aanskoue, verseker word dat dit nie ongekend is vir die gevoel om as 'n uitgestelde reaksie op te bloei nie, volgens allerlei omstandighede. Mense word deur romanskrywers en media kondisioneer vir 'n aardskuddende "love at first sight"' respons, maar baie ouerpare sal getuig dat dit dae, weke en selfs maande geneem het voordat volle ouerskapsbesef posgevat het. Hulle behoort hieroor van skuldgevoel en die inhiberende effek daarvaan onthef te word voor verdere afbreuk intree. As die moeder egter na verloop van die puerperium en herstel van swangerskap en geboorte nog oppervlakkige of bizarre verbintenis toon, behoort dit in 'n ernstige lig beskou en behandel te word.

Een van die werkopdragte van 'n Gevorderde Verloskunde- en Neonatale Sorg Kursus was om 'n ideale kraamhospitaal te ontwerp. 'n Interessante voorstel was 'n kompromis-idee oor die ietwat rusversteurende aspekte van 'm multibed-saamblybeleidsaal. Die plan het voorsiening gemaak vir 'n "skakelafskorting", as deel van 'n vierbedsaal vir moeders en babas. Meestal verkies die moeders om nie alleen te wees nie, veral wanneer hulle eie babas nog nie gesond genoeg is om by hulle te wees nie. Na-operatiewe en moeders met abnormale of doodgebore babas verkies soms enkelsale om ontstellende vrae te vermy. Menige vriendskap ontstaan tussen die jong moeders.

Dit mag dit moontlik maak om by tye stil slaapure te vereenselwig met aanvraagvoeding en moedersorg, sodat die fisiologiese prosesse wat slegs tydens normale slaap plaasvind (met inbegrip van ensiemfunksie vir hormoonsintese) kan plaasvind. Die idee is gegrond op beginsel dat eie ma (viz. Salomo) bykans eerste sal reageer op eie baba se huil soos ooi en eie lam mekaar spesifiek herken. Die baba kan dan snags, in die skaarse rustye van hedendaagse hospitale, effens apart geneem word, maar hoorbaar en beskikbaar bly.

Die instelling van ouerkunde-lesse, gesondheidsonderrig en voorkomende maatreëls, sowel as instruksie en toesig oor die hantering van 'n klein baba gee die moeder die selfvertroue om tuis vir haar kind te sorg. Die sielkundige

\begin{tabular}{|c|c|c|c|}
\hline Verbintenis & \multicolumn{3}{|c|}{ Moeder se gedrag teenoor baba } \\
\hline Telling & Voorkoms & Spraak & Doen \\
\hline $\begin{array}{l}\text { 1. Sterk } \\
\text { negatief, } \\
\text { onvanpas }\end{array}$ & $\begin{array}{l}\text { Algemeen: terneergedruk, } \\
\text { angstig, kwaai, apaties }\end{array}$ & $\begin{array}{l}\text { Maak neerhalende opmerkings } \\
\text { oor baba en vader; teleur- } \\
\text { stelling oor baba se geslag, } \\
\text { gedrag en voorkoms }\end{array}$ & $\begin{array}{l}\text { Soek en vestig } \\
\text { aandag op haarself; } \\
\text { wil alleen wees: } \\
\text { huil }\end{array}$ \\
\hline $\begin{array}{l}\text { 2. Matig } \\
\text { negatief, } \\
\text { onvanpas }\end{array}$ & & & \\
\hline $\begin{array}{l}\text { 3. Matig } \\
\text { positief, } \\
\text { paslik }\end{array}$ & & & \\
\hline $\begin{array}{l}\text { 4. Sterk } \\
\text { positief, } \\
\text { paslik }\end{array}$ & $\begin{array}{l}\text { Vreugdevol, uitgelate, } \\
\text { geesdriftig, kalm, trots, } \\
\text { goedversorgd }\end{array}$ & $\begin{array}{l}\text { Gesels direk met baba, } \\
\text { noem op naam, maak } \\
\text { positiewe stellings }\end{array}$ & $\begin{array}{l}\text { Hanteer baba; strek arms } \\
\text { uit wanneer kind aan } \\
\text { haar gegee word; vertroetel baba; } \\
\text { bewonder en maak oogkontak. }\end{array}$ \\
\hline
\end{tabular}


reaksies in die vroeë puerperium en die heraanpassings van gesinslewe is belangrike aspekte vir verdere onderlinge verrykende verhoudings met ouers en siblinge.

Die eensaamheid van tuiskoms met ' $n$ eersteling en die "stress" van die onervare moeder word weerspieël deur die gewildheid van Borsvoeding- en Gesonde Babaklinieke, waar soms sommer baie geselskap gehou word waar vordering — fisies sowel as psigologies — tog vasgestel word, terwyl die uitruil van ondervindings en die bespreking met die verpleegkundiges gerusstellend is.

Vroeë bespeuring van gebrekkige of wanontwikkeling van die moeder-kind verhouding $k$ an lewenslange probleme vermy. Daar word na die aanvangsaanhaling verwys.

Ons hanteer hulle in hulle oneindige individualiteit en verskeidenheid en van Madonna-kompleks tot aardsmoeder. Die seksoloë beklemtoon die ingrypende effek van suksesvolle huweliksheraanpassing en verpleegkundiges is terdeë bewus van die verskil tussen effektiewe herkenning en paslike verwysing en die volstruis-kop-in-die-sand en "passing the-buck" intervensie.

Dit is 'n groot verantwoordelikheid maar ook 'n wonderlike voorreg om in onsself die stamina vir voortdurende betrokkenheid te ontwikkel sodat 'n filosofie van toegeneë beskikbaarheid gevolg kan word. Laat alleraard verpleegkundige wat so dikwels in loco parentis ageer, hulle ding ken!

Diegene wat tot hier gelees het sal wel in die verloop van hul studies en loopbane kennis opgedoen het van fisiologiese-, psigologiese- en sosiale groei en ontwikkeling; slegs ouers wat "hartstilstand" gehad het oor 'n kind en moeders wat by hulle siek kind gewaak en gebid het, begryp die volle allesoorweldigende mag van ouer-kind verhoudings. Hulle wat met die betrokke literatuur vertroud is, sal weet watter onbegonne taak dit sou wees om kronologies verder te gaan binne die bestek van die opdrag vir hierdie skrywe.

Enige waarde hieruit word blymoedig opgedra aan dié wat gelukkig genoeg is om welgeskape, welgebore, welkome kinders te hê as Gods rykste seen.

"Diegene wat dinge sien groei van die begin af, sien dit die fynste."

- Aristoteles

\section{LEESLYS}

Die pasgebore Baba, Keet/Shore/Harrison

Textbook for Midwives, M. Myles.

A Mothers' Centre, Patsy Turrine

Psychological Needs of the Mother in Early Mother-Infant Interactions, Amols Sameroff

Attachment, J Bowlby.

Prenatal Determinants of Behaviour, J. M. Joffe.Maternal Child Bonding, Klaus and Kennell

Basic Maternity Nursing, P.M. Hamilton.

Nursing of Families in Crisis, Hall and Weaver.

Child Development and Personality, Mussen/Conger/Kagan.

'n Band vir Lewe en 'n Leeftyd, Kareni Bannister.

The Myth of the Divine Child, C.J. Jung and C. Kerenyi

Psychology of Character, Rudolph Allers.

Somato-psigiese Ulitwerking van Swangerskap, I. E. Cronjé.

Child Abuse and Battering, Kennell and Klempke 